\title{
The Evaluation of Different Learning Tools in Flipped Mechanics of Materials
}

\section{Dr. Sarira Motaref P.E., University of Connecticut}

Sarira Motaref is an associate professor in residence in the Department of Civil and Environmental Engineering at the University of Connecticut. She serves as Assistant Director of faculty development at the School of Engineering. She has been teaching large classes such as CE 2110 (Applied Mechanics I) and CE 3110 (Mechanics of Materials) which are major requirement across multiple disciplines in the School of Engineering since 2013. She has led the efforts within the Department to develop and deliver flipped sections of undergraduate courses. She is a licensed professional engineer. She has attended several teaching workshops and received certificates from UConn CETL (Center for Excellence in Teaching and Learning) and NETI (National Effective Teaching Institutes). Sarira is recipient of 2019 Distinguished Engineering Educator Award at the University of Connecticut, Winner of 2010 James D. Cooper Student Award at the International Bridge Conference, recipient of 2016, 2017, 2018 Klewin Excellence in teaching award and 2016 nominee for Mentorship Excellence Award from UConn office of undergraduates. 


\title{
The Evaluation of Different Learning Tools in Flipped Mechanics of Materials
}

\begin{abstract}
The Mechanics of Materials course has been offered in flipped modality for the past few years at the University of Connecticut. The main objectives for developing this flipped course were to enhance the learning quality in large-enrolment classes and to promote inclusive teaching by providing online course contents to all students. However, there were obstacles observed in offering flipped engineering courses in large classes (over 100 enrollments), such as providing efficient interactions between teacher-student and student-student, aligning students' progress with the class schedule, and maintaining class engagement. In addition, lack of 3-dimensional visualization, repetitive conceptual mistakes, and plagiarism in homework submissions were seen among students in this engineering classroom. Different learning tools have been tried and tested by the instructor during the past 6 years to address the above obstacles, enhance active participation of students, and improve students' class experience. The success or failure of these methods has been evaluated through the data collected as part of formal and informal students' evaluation of teaching (SET).
\end{abstract}

The course contents are delivered via short videos outside of class. The class time is used to review more challenging concepts and includes a short recitation of the lecture material followed by problem solving done by the instructor and the students individually or in groups. The mid semester evaluation of the class revealed that more than 75 percent of students prefer the flipped class over traditional teaching. They indicated that problem solving activities and lecture videos are the most beneficial class components in the students' learning.

To enhance the students' visualization, foam models and Augmented Reality (AR) are being used. Only 50 percent of students found AR activities (using their smart device) helpful.

Pictures from real life applications of each engineering topic were collected and shared via social media (Facebook) in the past classes. Few students showed interest to share pictures or comment on the class Facebook page. Students' participation increased when these pictures were displayed and discussed during class.

Smart Book (containing the online homework platform) was replaced by old fashion paper submission. This platform was selected by the instructor to address the issue of plagiarism as it offers algorithmic problems to each student. The survey showed that more than 80 percent of students prefer the online homework platform (due to instant feedback and comfort of multiple submissions). The teacher assistants were able to spend their time interacting with each student rather than grading homework.

Class assessments include online quizzes, midterm exams, and in-class assignments. The main objectives for in-class assignment are encouraging students to watch videos before attending the class and interacting with peers. More than 70 percent of students claimed that team effort enhances their learning and class experience.

The students' perception about effectiveness of each learning tool, the rate of class attendance in sequential semesters, and students' participation in class activities will be compared and presented. Other techniques used to minimize common engineering errors among students will be shared. 


\section{Hypotheses and nature of data}

This work is aimed to evaluate if the inclusion of non-traditional teaching and assessment methods, such as teamwork activities, problem visualization, and physical models improve students' participation in a basics mechanics course.

To investigate these hypotheses, the evaluation data from the class participation and student evaluation of teaching (SET) are summarized and critically discussed. Because the evaluation activities used to inform this paper are limited to "systematic collection of information about the activities, characteristics and outcomes of programs to make judgments about the program (or processes, products, systems, organizations, personnel, or policies), improve effectiveness, and/or inform decisions about future program development," [1] the author did not seek an IRB approval.

This paper reviews the obstacles observed in offering a flipped undergraduate engineering course in the past 6 years, an overview of potential solutions and implementation methods in a large enrollment class, and major findings based on student perceptions of the activities. It is expected that discussing incorporated methods in the flipped classroom to address each challenge, along with providing effectiveness of each method in students' participation and enhancing the class experience, will help other instructors to add similar activities to their engineering flipped courses in an effort to improve learning quality.

\section{Background and components of flipped classes}

The Mechanics of Materials course is a major requirement for many engineering disciplines including Civil, Mechanical, Biomedical, Material Science, Management and Manufacturing Engineering, and Engineering physics. A flipped classroom offers many advantages to both faculty and students. Inverting the classroom means that events that have traditionally taken place inside the classroom now take place outside the classroom and vice versa [2]. The class has large enrollments of 100 to 120 students per section and an annual enrollment of 400 students. Considering the limited faculty resources and available space, the flipped version of the class was developed in 2013 to enhance the quality of the course, share uniformed resources to all students and provide alternative learning resources for diverse learners. Herreid and Schiller explained the flipped classroom as an educational technique that consists of two parts: interactive group learning activities inside the classroom, and direct computer-based individual instruction outside the classroom [3].

In this flipped course, each lecture is presented with a pair of videos including a lecture video that presents the concept and formulations followed by a sample solving video where 2 or 3 problems are solved in step by step format. The videos are usually 10 to 15 minutes long to maintain students' attention. A total of 34 lecture videos and 34 sample solving videos are available for this course.

The course assessments include weekly homework, bi-weekly multiple-choice quizzes, 3 midterm exams and 1 comprehensive final exam. A detailed class calendar displaying the topic of each day is shared with the students at the beginning of the semester.

The class activity includes a short lecture by the instructor about the topics of the day followed by problem solving by students. Students are provided a handout that contains related homework 
problems and a few problems with a higher level of difficulty in each class. Solutions to these problems are posted at the end of each week. The instructor and his/her teacher assistant guide students during problem solving activities and present the correct solutions on the board.

\section{Challenges in the flipped classroom}

Although flipped classrooms can have many advantages, some issues, such as student resistance to this model and the time required on the part of the instructor to integrate out-of-class and inclass elements, have been identified; thus leading some instructors to question the value of changing to a flipped classroom [4]. This section presents some challenges observed in the flipped classroom, the new components implemented in the class to address the issues, and findings based on students' feedback or comparison of students' performance enrolled in different semesters.

Class attendance and lack of preparedness: Due to the availability of the course materials in the form of videos, class attendance was decreasing after a few weeks from beginning of the semester. Although, problem-solving activity was offered during class time, only about $50 \%$ of class were attending the classroom and the rest did not participate consistently. In addition, students were not necessarily watching videos before attending class.

A great number of engineering students work alone. But in industry, teamwork is required most of the time. Incorporating Cooperative Learning (CL) into an engineering program gives students an opportunity to practice problem solving and communication skills in a 'simulated' professional environment [5], [6]. It was expected that an assessment activity to evaluate students' learning (on topic of the day) during class time may motivate students to watch videos before attending the class, promote peer interaction, and increase class attendance. To test this hypothesis, a low stake graded teamwork assignment was added to the class requirements.

Students are assigned to team of 3 to answer a question related to the topic of the day in 15 to 20 minutes. This activity encourages students to be prepared before the class by watching assigned videos. It also enables students to practice a simulated mini exam (a timed activity with the same level of difficulty) in this low stake assignment. Team members rotate to allow students to meet different peers and experience working with different backgrounds. The instructor and teacher assistants check students' work, inform each team about mistakes and provide guidance during this activity. This teamwork assignment is randomly offered once a week during the semester.

Teamwork activity was offered to students enrolled in class in 2018 and 2019. Table 1 summarizes students' feedback on effectiveness of this activity in their learning collected from class mid semester surveys. More than $70 \%$ of students agreed or strongly agreed that the teamwork activity is beneficial in their learning.

Table 1. Responses from initial class survey on if teamwork activity is beneficial to students' learning $(\%)$

\begin{tabular}{ccc}
\hline Academic Year & Agree and Strongly agree & Disagree and Strongly disagree \\
\hline 2018 & 73.4 & 26.6 \\
\hline 2019 & 72.4 & 27.6 \\
\hline
\end{tabular}

To evaluate impact of this activity in class attendance, a question from final class SET about number of missing classes was studied. Table 2 displays students' response to the question "How 
many times did you miss this class?" Average of 50\% of students have responded to the final SET in each survey.

The data is presented in Table 2 for the classes in which the teamwork activity was not offered $(2014,2015,2016$ and 2017) and for classes where the teamwork activity was required (2018 and 2019).

Table 2. Percentage of students missing classes in classes offered from 2014 to 2019

\begin{tabular}{lrrrrr} 
& \multicolumn{5}{c}{ Number of missing classes } \\
\hline Academic year & $\mathbf{0 - 2}$ & $\mathbf{3}$ to $\mathbf{4}$ & \multicolumn{2}{|c}{ to } & \multicolumn{1}{c}{$\boldsymbol{>}$ 6 } \\
\hline Spring 14 & 62.0 & 18.0 & 15.0 & 5.0 \\
\hline Spring 15 & 68.0 & 19.0 & 5.0 & 7.5 \\
\hline Fall 15 & 56.5 & 26.5 & 7.5 & 10.0 \\
\hline Fall 16 & 58.0 & 33.0 & 6.0 & 3.0 \\
\hline Fall 17 & 32.0 & 35.0 & 18.5 & 15.0 \\
\hline Fall 18 & 67.0 & 23.5 & 2.5 & 7.0 \\
\hline Fall 19 & 63.5 & 29.5 & 2.0 & 5.0 \\
\hline
\end{tabular}

A significant reduction was observed in percentage of students who were absent 5 to 6 times or more than 6 times during fall 2018 and 2019 when the teamwork activity was offered. comparison of data for two subsequence academic years of 2017 and 2018 revealed that percentage of students missing more than 6 classes was reduced from $15 \%$ to $7 \%$ which is equivalent to $53 \%$ reduction.

Students' visualizations: Previous studies have shown that accurately visualizing objects in 3Dimension (3D) improves spatial understanding [7], which has been associated with success in engineering programs. This visualization can help students learn materials permanently and improve their creativity [8]. One option for improving visualization and spatial skills is providing opportunities for students to interact with handheld models.

It was observed that students' performance was affected due to their struggle with 3D visualization skills. Most students were not able to identify the actual shape of a complicated structure based off 2 dimensional (2D) figures, therefore they had difficulty to collect required information to solve the problem correctly. In addition, students were not motivated to find the application of concepts in design of real-life objects.

It was assumed that using 3D demonstrations of elements may help students to better comprehend engineering problems. To evaluate this hypothesis, a few visualization methods were implemented in the flipped classroom including:

a) Instructor built simple foam models to show design details and potential loadings and stresses. Figure 1 shows sample foam models used in Mechanics of Materials course. The instructor displays and interacts with the foam models during lectures to visually show deformation and failure modes. More than $80 \%$ of students reflected in SET data that these foam models very helpful in their learning. However, they suggested that letting them to interact with the models will be more beneficial. 


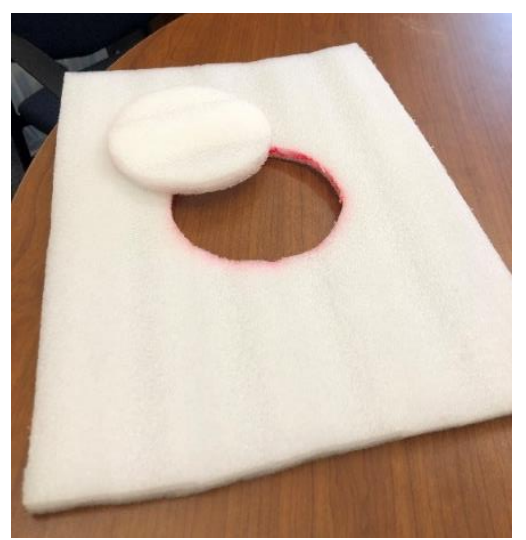

(a)

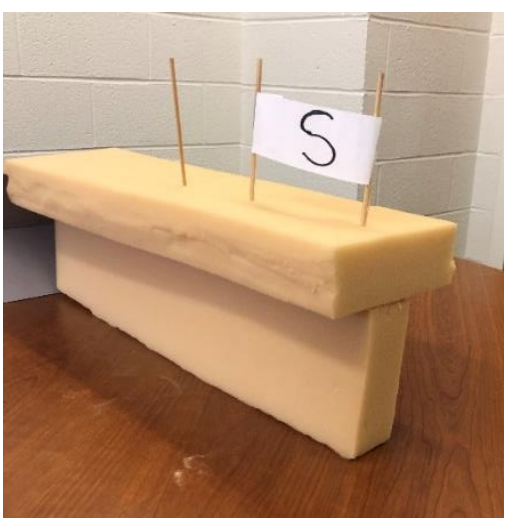

(b)

Figure 1. Foam models to demonstrate engineering concepts a) shearing stress in punching,

b) design of connection in built-up members

b) Related pictures from real life examples of engineering topics or catastrophic failure due to poor design are shared with students to enhance $3 \mathrm{D}$ visualization and engineering evaluation skills (Figure 2).

A Facebook page was created for the classroom and students were asked to find application of concepts in their surroundings, take a photo and post to a web page. This activity was not well received by students; Later they expressed that mixing their academic life and personal life in social media is not ideal. Also, they were resistant of sharing their observation as they did not want to be judged by other viewers.

It was decided to share these real-life examples during class short recitation. Students are asked to use the Think-Pair-Share method to discuss each picture. Figures 2 (a) ad (b) display examples of failure under bending and buckling in slender members, respectively. More than $70 \%$ of students found real-life pictures helpful in their leaning and said that "Real life examples showcased how theory applies in the world around us, making concepts more understandable".

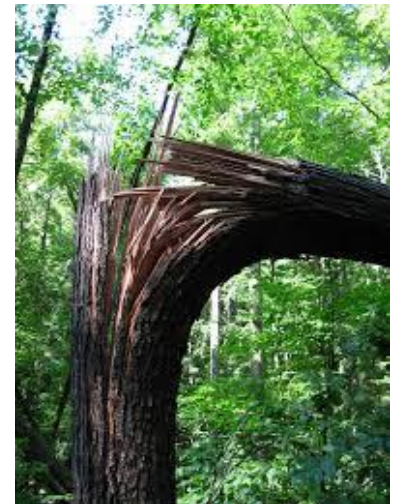

(a)

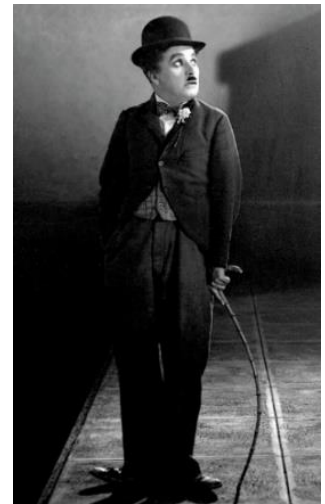

(b)

Figure 2. Real life examples of engineering concepts, a) Failure under bending in a tree, b) Buckling in Charlie Chaplin's cane [9], [10]

c) A few challenging problems from each chapter of the textbook that former students expressed difficulty in visualization were selected. SketchUp 3D modeling software was used to build the corresponding models. Models were launched and stored in an online application (Sketchfab) 
and shared with students. In the first half of the semester, students were asked to install Sketchfab (offers Augmented Reality) on their smart device (Figure 3 (a)). Students were watching and interacting with models on their cellphones during the lecture. Results of the midsemester survey revealed that only $50 \%$ of students agreed or strongly agreed that AR is helpful with their learning. Many of students suggested that the instructor displays models on the board using a projector (Figure 3 (b)) and incorporate the models in class discussion. Therefore, in the second half of the semester, 3D models were integrated with the lecture. The Final SET revealed that $70 \%$ of students found 3D models helpful with their performance when it is presented and explained by the instructor.

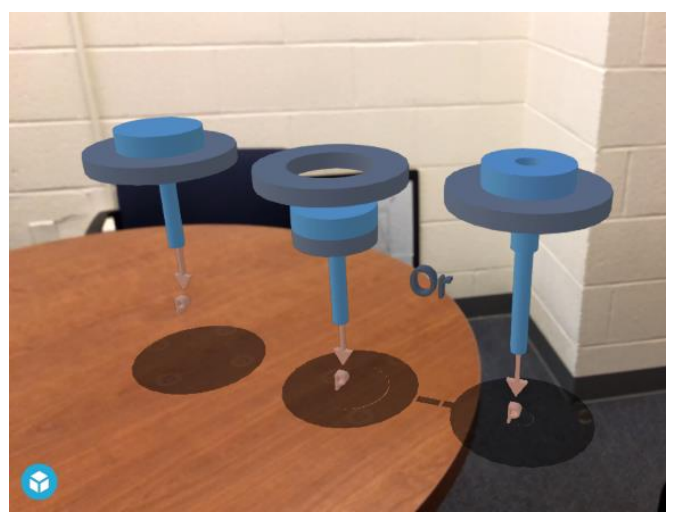

(a)

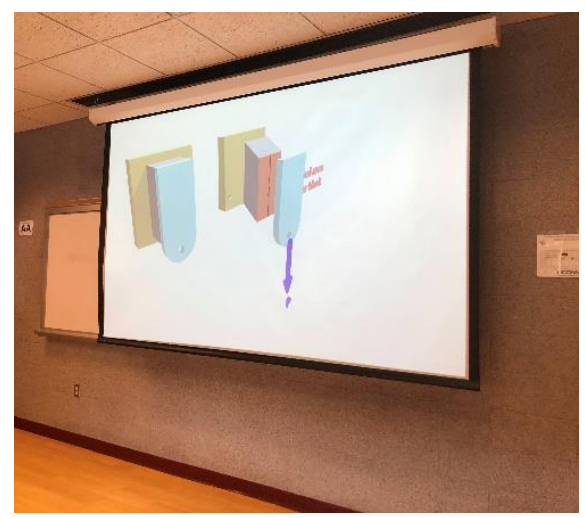

(b)

Figure 3. 3D models presentation, a) Augmented Reality using Sketchfab application, b) Class presentation using monitor and projector

Summary of students' feedback (collected from both class mid-semester survey and final SET) about each visualization method and weather they found it helpful in students' learning is presented in Table 3. As a result, students found foam models, pictures from real life application of engineering concepts and 3D models presented by the instructor as the most helpful tools in their learning.

Table 3. Students' feedback on helpfulness of different visualization methods (percentage)

Agree and Strongly agree

Disagree and Strongly disagree

\begin{tabular}{lcl}
\hline Foam models & 82 & 18 \\
\hline Facebook page & 3 & 97 \\
\hline Pictures integrated in lecture & 75 & 25 \\
\hline AR models via students' smart device & 52 & 48 \\
\hline AR model integrated in lecture & 70 & 30 \\
\hline
\end{tabular}

Plagiarism in Homework assignments: It was observed by the instructor team that some students have access to the homework solutions (online resources) or they just simply copy from other peers. Identifying such misbehavior was challenging in large enrolment classes. In addition, those students were not benefiting the homework activity towards their learning.

Students are required to submit weekly homework (solve 5 to 6 problems related to the topics selected from the textbook) at the end of each week. There have been 3 methods of homework submission employed in this course over the past 6 years including paper submission, electronic file submission in blackboard system, and online assignments via smart book. 
Paper submission was required in 2013 and 2014. This method was not efficient as the students' performance was not documented electronically. Collecting, grading and returning graded homework was time consuming in a large class, and feedback to student's work was not immediate.

To further organize the homework submission, students were asked to submit homework as a pdf file using the Blackboard system during 2015 and 2016. Teacher assistants were able to provide feedback electronically. But this method still did not provide immediate feedback. Students were able to access their graded homework anytime via Blackboard.

Previous studies showed that online homework is a useful and worthwhile tool in college courses, and that instructors can potentially design homework to help students derive maximum benefits. Because students appreciate feedback and flexibility, assignments should be set up to provide these features. Where appropriate, an explanation of why an answer is correct, the strategy for solving a problem, or even a reference to a page in the textbook may be incorporated into the system [11]. Online assignments via smart book (McGraw-Hill Connect) were implemented in the course during 2017, 2018 and 2019 to address past challenges including plagiarism, delayed feedback, and time-consuming task of grading for large enrollments. Online assignment platform offers algorithmic, auto graded homework assignments. All students answer the same problem; however, the numerical parameters are different. This system prevents students from copying solutions. However, the effect of using online assignments in minimizing plagiarism is not studied here. Students were able to check their work before submission and get access to the textbook resources. In addition, the auto graded feature eliminates the number of hours required for grading. Solution to homework is available after the deadline. Students provided very positive feedback to this new platform. $82 \%$ of students expressed in the class mid semester survey that online homework (via smart book) is a better learning tool compared to the traditional submission (paper or electronic file). The only downside is that students cannot receive partial credit as they only insert the final answers for each problem.

The average number of students failed to submit their homework and the average homework grades for different submission methods over sequential semesters are studied and presented in Figures 4 (a) and (b). The average class enrollment was 100 students in each course offering. The results showed that fewer students may miss homework submission when online assignment was incorporated. There was no significant difference observed in students' average homework grade when different submission tools were used in the course (Figure 4 (b)).

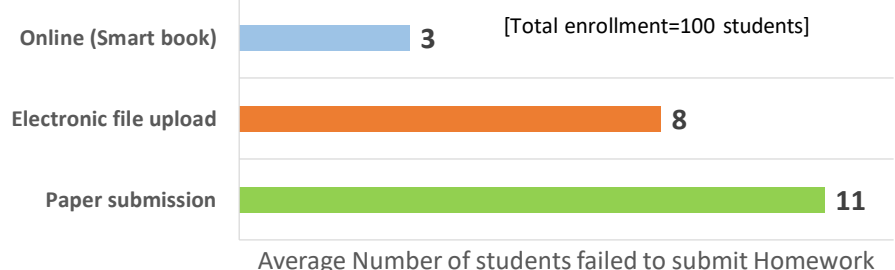

(a) 


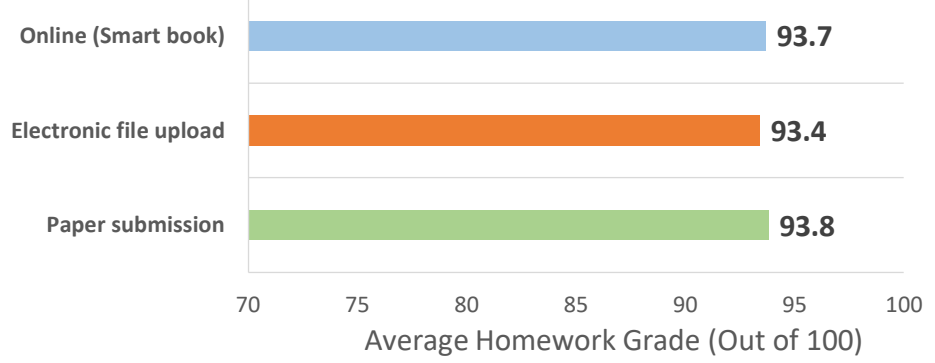

(b)

Figure 4. a) Average number of students missing homework submission, b) Average homework grade (out of 100)

Effect of midterm and final exam on final course grade: In earlier class offerings, it was required for all students to take 3 midterm exams and a final exam. Per course policy, $45 \%$ of the total grade is calculated based on 3 midterm exams (15\% each) and final exam (20\%). It was observed that the students' final grade is significantly affected if they perform poorly in some midterm exams. Instructor believes that students should be given a second opportunity to learn and be examined repeatedly until they master that topic. Students' record showed that students perform well in the final if they have performed consistently well in midterm exams. To test this assumption a few changes were made in the exam policy to reward hard working students and to provide a second opportunity to students who struggle in the course.

In the new policy, final exam is optional. Students who have received satisfying grades in the 3 midterm exams will be exempt from the final exam. This policy encourages many students to work hard during the semester and perform well consistently. Other students can take the final exam and use its grade to be replaced with their lowest midterm exam. Students expressed that this policy kept them motivated and hopeful that by working hard, they can still do well in the course. In fall 2019, approximately 40 percent of students chose to attend the final exam to enhance their final grade. The data showed that students enhanced their final grade by average of 6 points with range of 0 to 14 points by using this policy.

To evaluate effectiveness of this policy to motivate more students performing well consistently during the semester, number of students receiving grades $90-100$ from midterm exams were compared for the classes with and without this policy. Figure 5 shows the data for students enrolled in fall 2017 which attending final exam was required versus who were enrolled in fall 2019 which students could be exempt from the final exam. Due to this rewarding policy, 32 students in fall 2019 received a satisfactory grade in Midterm 1 (Earliest assessment) compared to 13 students in fall 2017. It can be concluded that this policy may motivate more students to work hard consistently through the semester to master the materials. 


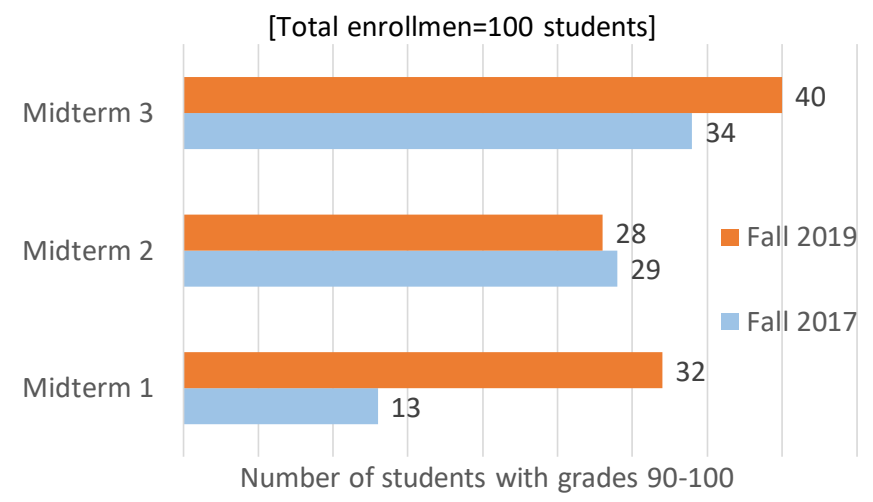

Figure 5. Number of students with grades 90-100 for classes in fall 2017 and fall 2019

Repetitive conceptual errors among students: There were specific topics such as the analysis of composite sections under a different type of loading, indeterminate structure analysis, and second moment of inertia calculation that repetitive conceptual errors were observed in the midterm exam assessments.

To address these common errors, 1) sample exams containing solutions and rubrics were shared with students, 2) possible errors were reminded and emphasized in problem solving activity during the lecture, 3) Case study displaying correct and incorrect approaches to solve a problem was discussed during the lecture. To evaluate effectiveness of these methods, the instructor recorded the number of students making conceptual errors for a selected topic (analyzing a composite element under axial loading) during different course offerings. Before the implementation of a case study, more than $60 \%$ of exams contain conceptual error for the selected topic. After implementing the case study ( $3^{\text {rd }}$ method), percentage of students making conceptual errors reduced to $18 \%$. It was concluded that the case study is a promising method to minimize common conceptual errors observed in the exam.

\section{Conclusions}

The flipped version of Mechanics of Materials was developed in 2013 and has been offered in the past 6 years. There were obstacles observed in offering this flipped course (with large enrollment over 100 students) such as providing efficient interactions between teacher-student, student-student, maintaining class engagement, lack of 3D visualization, repetitive conceptual mistakes, and plagiarism in homework submissions. Different learning tools have been tried and tested by the instructor to address the obstacles, enhance active participation of students, and improve students' class experience. The following findings were concluded:

- Offering graded teamwork activities encouraged students to be prepared for the topics by watching lecture videos before attending the class. A significant improvement was observed in class attendance. More than $75 \%$ of students agreed or strongly agreed that the teamwork activity is beneficial to their learning. The number of frequent absentees reduced by $53 \%$.

- To strengthen students' visualization skill, different learning tools were incorporated. Foam models were built and displayed. Real life examples of engineering applications were shared with students. 3D models of complicated problems were presented via Augmented Reality (Sketchfab) or by using a projector during lectures. More than $80 \%$ of students considered the foam models very useful in their learning, However, they suggested that letting them to 
interact with the models will be more beneficial. SET results showed that $70 \%$ of students found 3D models and real-life engineering application pictures beneficial to their learning.

- $82 \%$ of students found online homework (via smart book) a better learning tool compared to traditional submission. The results showed that fewer students may miss homework submission when online assignment was incorporated. There was no significant difference in students' average homework grade when different submission tools were used in the class.

- The optional final exam policy encouraged students to work hard during the semester and kept them motivated even if they do poorly in one of the midterm exams. A significant increase was observed in number of students motivated to work hard from the beginning of semester by comparing the data collected from the class that this policy was offered versus past classes. The data showed that students attending final exam were able to enhance their final grade by average of 6 points.

- The most effective method to minimize conceptual errors was using a case study displaying correct and incorrect solutions during lecture. $70 \%$ reduction was observed in the number of students making such errors for a specific topic by comparing the students' performance from the class that this method was implemented respect to the past classes.

\section{Acknowledgment}

Author would like to thank the Center for Excellence in Teaching and Learning at the University of Connecticut to help with building the flipped version of the Mechanics of Materials Course. Editorial review by Raha Esmaili Zaghi and Dr. Arash Zaghi is much appreciated. The former students of this course are greatly appreciated as addressing the challenges and improving the course quality were not possible without their feedback.

\section{References}

[1] https://ovpr.uconn.edu/services/rics/irb/researcher-guide/does-evaluation-require-irbreview/\#

[2] M.J. Lage, G.J. Platt, and M. Treglia, "Inverting the classroom: A gateway to creating an inclusive learning environment", The Journal of Economic Education, 31(1):30-43, 2000.

[3] C. F. Herreid and N. A. Schiller, "Case Studies and the Flipped Classroom", Journal of College Science Teaching, Vol. 42, No. 5 (), pp. 62-66, May/June 2013.

[4] B. Kerr, "The flipped classroom in engineering education: A survey of the research," Proceedings of 2015 International Conference on Interactive Collaborative Learning (ICL), 2024 September 2015, Florence, Italy

[5] Bishop, J. L., \& Verleger, M. A. (2013, June). The flipped classroom: A survey of the research. In ASEE national conference proceedings, Atlanta, GA (Vol. 30, No. 9, pp. 1-18). [6] N.J. Mourtos, "The nuts and bolts of cooperative learning in engineering," Proceedings of 1994 IEEE Frontiers in Education Conference - FIE '94, San Jose, CA, USA, USA

[7] P. Schuchardt and D. A. Bowman, "The benefits of immersion for spatial understanding of complex underground cave systems," in Proceedings of the 2007 ACM symposium on Virtual reality software and technology, 2007: ACM, pp. 121-124.

[8] B. Carey, "How we learn: the surprising truth about when, where, and why it happens", Random House Trade Paperbacks, 2015. [9] https://images.app.goo.gl/SaAbK99axcaZEK8R8 [10] https://www.dnr.state.mn.us/forests_types/oldgrowth/description.html 
[11] D.J. Doorn; S. Janssen, M. O'Brien, "Student Attitudes and Approaches to Online Homework," International Journal for the Scholarship of Teaching and Learning, v4 n1 Article 5 Jan 2010. 